\title{
Resistência à remoção de braquetes ortodônticos sob ação de diferentes cargas contínuas
}

\author{
Carla Giannini*, Paulo Afonso Silveira Francisconi**
}

\begin{abstract}
Resumo
Objetivo: testar se existe alteração na resistência adesiva de dois cimentos utilizados na colagem de acessórios ortodônticos ao esmalte dentário bovino, sendo um de polimerização química (Concise ortodôntico) e outro fotopolimerizável (Transbond XT), após a aplicação de cargas contínuas. Metodologia: foram utilizados para este estudo 80 dentes bovinos e 80 braquetes metálicos. O esmalte bovino foi condicionado com ácido fosfórico a 37\% por 1 minuto e depois lavado e seco. A aplicação dos adesivos, manipulação e aplicação dos dois cimentos foram feitas de acordo com as instruções dos fabricantes. Após 24 horas, todos os braquetes foram submetidos a cargas contínuas de $30 \mathrm{~g}$, $70 \mathrm{~g}$ e $120 \mathrm{~g}$, menos o grupo controle, que não recebeu carga alguma. Os espécimes ficaram imersos em água filtrada por 28 dias dentro de uma estufa a $37^{\circ} \mathrm{C}$. Depois deste período, as amostras foram submetidas a testes de cisalhamento em uma Máquina de Ensaios Universal Kratos. Os resultados foram registrados e enviados para análise estatística. Conclusões: (1) o cimento Concise apresentou maior resistência à remoção que o cimento Transbond XT para todas as cargas utilizadas, (2) não houve diferença estatisticamente significante na resistência adesiva frente às três cargas utilizadas para os dois cimentos testados; (3) no momento da fratura, conforme ocorreu o aumento da carga, a porcentagem de fratura do esmalte diminuiu para o Concise, ao contrário do cimento Transbond XT, onde a porcentagem de fratura de esmalte se manteve constante com o aumento das cargas.
\end{abstract}

Palavras-chave: Cimentação. Braquete ortodôntico. Adesão. Carga.

\section{INTRODUÇÃO}

Desde que Buonocore ${ }^{3}$, em 1955, propôs o condicionamento ácido do esmalte para aumentar a adesão entre a resina acrílica e o esmalte dentário, permitindo, indiretamente, o grande impulso à fixação de braquetes sobre a superfície do esmalte, esta técnica continua sendo uma rotina em Odontologia. Tornou-se, também, amplamente utiliza- da para a colagem direta de acessórios ortodônticos no esmalte dentário, ao invés da bandagem dos dentes, como ocorria anteriormente. Segundo Maijer e Smith ${ }^{11}$, em 1981, as resinas são utilizadas na colagem de braquetes, podendo-se dizer que "uma nova era ortodôntica - a Ortodontia sem bandas - foi inaugurada", ajudando muito a terapia ortodôntica. As bandas metálicas e o cimento não

\footnotetext{
* Especialista em Dentística Restauradora pelo HRAC-USP. Mestre em Dentística, opção Materiais Dentários pela FOB-USP.

** Mestre, Doutor e Livre-docente em Dentística, opção Materiais Dentários pela FOB-USP.
} 
causam apenas desconforto ao paciente, mas fazem o tratamento ficar mais complicado e desconfortável, necessitando de separação dentária antes da confecção e cimentação das mesmas, além de promoverem conseqüências indesejáveis, como inflamação gengival e descalcificação do esmalte ${ }^{14}$. Conseqüentemente, a técnica de colagem direta de acessórios ortodônticos ofereceu certas vantagens, como economia de tempo, melhor aceitação, melhor estética, além de se tornar mais acessível para o paciente e reduzir algumas fases do tratamento $^{12}$.

Após a aplicação de um ácido (na maioria das vezes o fosfórico a 37\%) sobre o esmalte dentário, ocorre a dissolução dos cristais de hidroxiapatita nele contidos, produzindo microporosidades, até que um monômero resinoso fluido possa penetrar ${ }^{5}$ nesses poros - o qual, quando polimerizado (de forma química, física ou físico-química), promoverá uma união micromecânica entre eles.

A união entre um acessório ortodôntico e um sistema adesivo resinoso é também uma união mecânica. Estudos ${ }^{8,18}$ foram realizados para aperfeiçoar os sistemas adesivos resinosos, pesquisando-se mais intensamente o mecanismo do condicionamento ácido na colagem e a resistência à tração de um braquete colado ${ }^{19}$.

A maioria das pesquisas desenvolvidas nessa área destina-se a comparar os diferentes tipos de cimentos resinosos utilizados para a colagem de acessórios ortodônticos ${ }^{1,4-12,14,15,16,18-23}$, bem como o tempo de condicionamento ácido ${ }^{19,22}$, resistência adesiva entre cimentos ${ }^{1,2,4-12,14,15,18-23}$, modos de fratura após a descolagem ${ }^{1,2,4,6-8,10,12,15-17,20-23}$, diferentes tipos de braquetes ${ }^{6,8,11,12,14,20,21}$ e de bases de

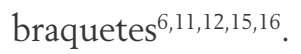

Porém, pouco se sabe se a ação de forças (mastigação, ação de alimentos pegajosos, a tensão que o fio ortodôntico exerce durante o tratamento e a própria oclusão), durante o período do tratamento ortodôntico, sobre os braquetes exerce alguma influência na resistência adesiva desses cimentos resinosos, podendo comprometer a terapia ortodôntica.
Esse fato motivou o estudo da colagem de braquetes sobre os dentes, com dois tipos de cimentos resinosos, sob a ação de diferentes cargas, simulando a força que o fio ortodôntico exerce sobre o braquete, ou mesmo a ação da própria mastigação ou de alimentos pegajosos durante a movimentação ortodôntica.

De acordo com o que se observou na literatura, a proposta deste trabalho foi: 1) testar se existe alteração na resistência adesiva de dois cimentos utilizados na colagem de acessórios ortodônticos ao esmalte dentário bovino, após a aplicação de cargas contínuas, mediante teste de cisalhamento; 2) observar se há diferença entre a resistência adesiva frente às diferentes cargas utilizadas $(0 \mathrm{~g}, 30 \mathrm{~g}$, $70 \mathrm{~g}$ e $120 \mathrm{~g}$ ) e 3) analisar o tipo de falha ocorrida no momento do deslocamento dos braquetes para os dois cimentos testados.

\section{MATERIAL E MÉTODOS}

Para a realização deste estudo foram utilizados 80 dentes bovinos, os quais tiveram suas raízes seccionadas, a fim de que suas coroas fossem posteriormente incluídas nos testes de cisalhamento e imersas em solução de Cloramina T a 1\%, para a armazenagem até o início da realização dos en$\operatorname{saios}^{20}$.

\section{Preparação dos corpos-de-prova}

Para a montagem dos corpos-de-prova foi necessário o uso de matrizes cilíndricas metálicas, as quais eram utilizadas para vazar silicona e, posteriormente, sobre essas matrizes era vertida a resina epóxica já com o dente bovino em posição.

Após a completa polimerização da resina epóxica (aproximadamente 24 horas), a matriz de silicona era, então, removida (Fig. 1A).

Uma vez removido o molde de silicona, os corpos-de-prova eram submetidos à planificação da superfície do esmalte em uma politriz com lixas d'água de granulações 320 e 600, respectivamente, para facilitar e padronizar a colagem dos braquetes (Fig. 1B). Também era ajustado o diâmetro das 



FIGURA 1 - A) Corpos-de-prova confeccionados em resina epóxica, B) planificados para facilitar a colagem dos braquetes e C) com seus diâmetros ajustados para perfeito encaixe na máquina de teste de cisalhamento.

amostras para que se encaixassem perfeitamente no dispositivo que seria, posteriormente, utilizado para o teste de cisalhamento (Fig. 1C).

Sendo assim, os corpos-de-prova estavam prontos para que se iniciasse, então, a colagem dos braquetes metálicos.

\section{Braquetes utilizados}

Foram utilizados neste estudo 80 braquetes metálicos de base plana (Morelli Ortodontia Braquete Edgewise/Rickets para colagem), com área de $12 \mathrm{~mm}^{2}$.

\section{Cimentos resinosos utilizados}

Para a colagem dos acessórios, foram utilizados dois cimentos resinosos diferentes: Sistema de Fixação Ortodôntico Concise (3M do Brasil, Sumaré - SP, Brasil), de polimerização química, e Transbond XT - Adesivo Ortodôntico Fotopolimerizável em Seringas (3M Unitek Orthodontic Products, Monrovia - CA, USA).

\section{Procedimento de colagem}

Os corpos-de-prova foram separados, após a colagem, em oito grupos com 10 dentes em cada, de acordo com as cargas e com os cimentos utilizados.

A colagem dos braquetes foi feita de acordo com as instruções dos fabricantes: condicionamento com ácido fosfórico a 37\% em gel, por 1 minuto, e rinsagem. Para o cimento resinoso Concise Ortodôntico foi feita, a cada colagem, a homoge- neização e aplicação das resinas fluidas, preparo da pasta de fixação e aplicação da mistura nas bases dos braquetes para serem levados em posição. Já para o cimento resinoso Transbond XT, após a secagem do esmalte, foram feitas as aplicações do Primer Adesivo e, em seguida, do cimento nas bases dos braquetes metálicos, para serem levados em posição.

Para se padronizar a força exercida na colagem $(453,6 \mathrm{~g})$ e a espessura da película de cimento, foi utilizada uma Agulha Maior de Gilmore sobre braquetes (Fig. 2), assim que os mesmos eram posicionados sobre os dentes. Com a mesma agulha em posição os excessos eram removidos antes da presa dos cimentos (Fig. 3). A fotopolimerização do cimento Transbond XT foi realizada com um aparelho fotopolimerizador Degulux Soft-start (Degussa), com intensidade de luz, aferida por um radiômetro (Demetron Research Corp.), de $450 \mathrm{~mW} / \mathrm{cm}^{2}$, aproximadamente, totalizando 40 segundos (10 segundos em cada face do braquete), conforme orientações do fabricante.

Todos os espécimes foram armazenados em água filtrada por 24 horas em estufa a $37^{\circ} \mathrm{C}$, antes da colocação dos pesos.

\section{Preparação para os ensaios}

Após 24 horas em estufa a $37^{\circ} \mathrm{C}$, cada grupo de dez braquetes, de cada material, foi submetido a diferentes cargas, representadas por pesos usados para pesca com 30g, 70g e 120g (Fig. 4), uma vez que a força necessária para realizar um movimen- 


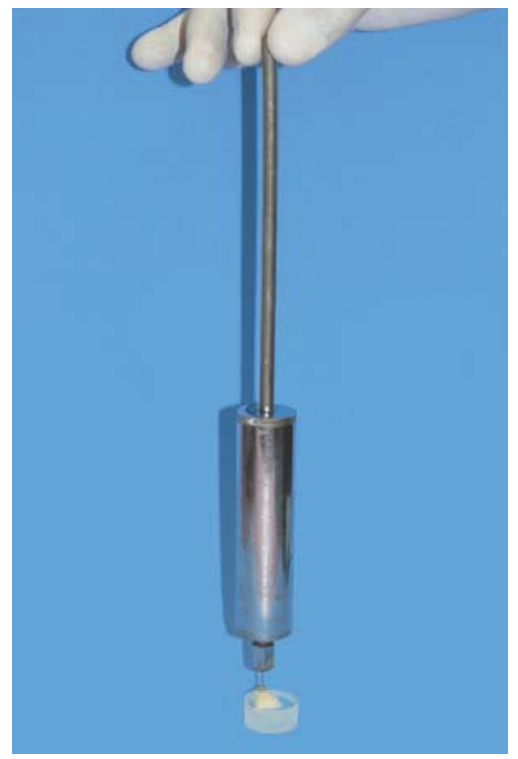

FIGURA 2 - Posicionamento da Agulha Maior de Gilmore para a padronização da força exercida no momento da colagem.

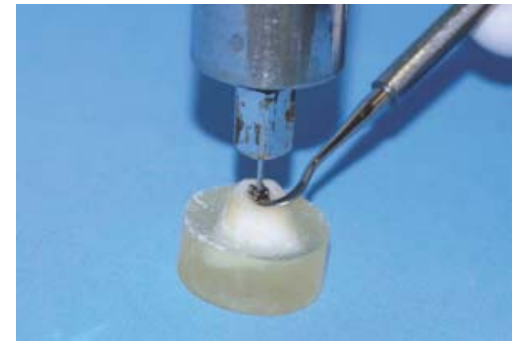

FIGURA 3 - Posicionamento da Agulha Maior de Gilmore, remoção do excesso de cimento.

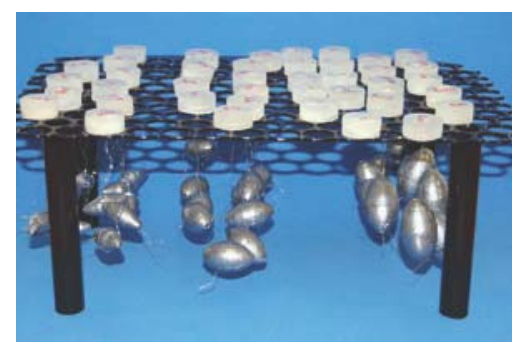

FIGURA 4 - Corpos-de-prova submetidos à tensão.
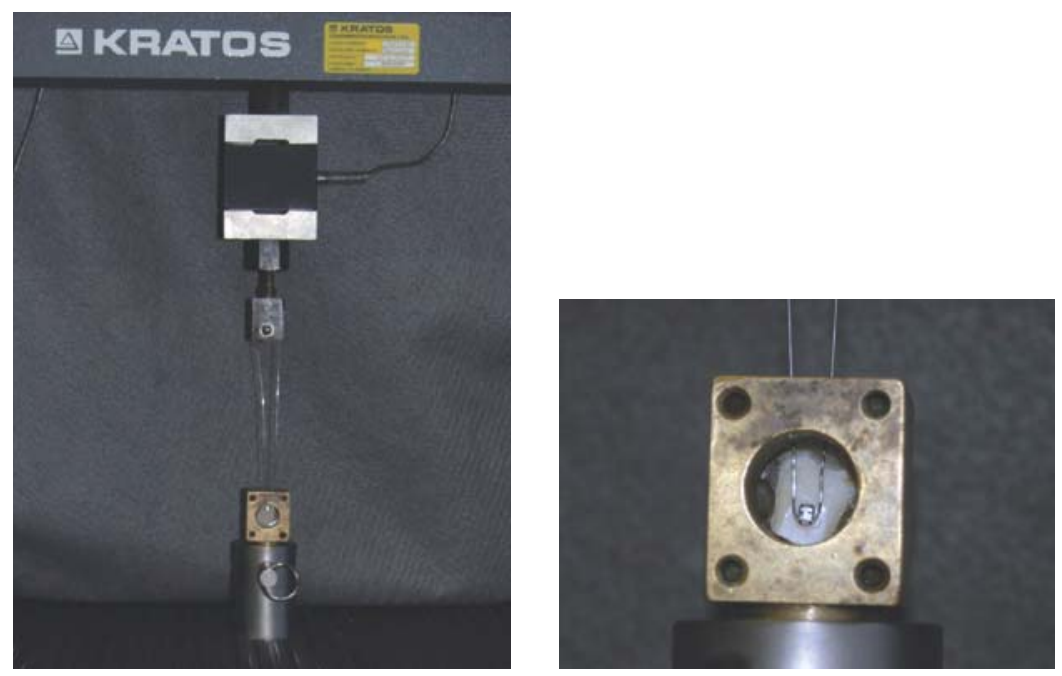

FIGURA 6, 7 - Corpo-de-prova acoplado à máquina de ensaios, pronto para iniciar o teste de cisalhamento.

FIGURA 5 - Imersão dos corpos-de-prova em água filtrada. 
to de inclinação dentária varia entre 50 e $75 \mathrm{~g}^{17}$, além do grupo controle onde o braquete não foi submetido a nenhum tipo de tensão.

Os pesos eram amarrados aos braquetes através de um fio de amarril 0,010" e eram deixados sobre um dispositivo (grelha) confeccionado especialmente para essa finalidade, gerando uma força, no braquete, de tensão. Essa grelha era encaixada dentro de uma caixa plástica para que os corposde-prova pudessem ficar imersos em água filtrada por um período de, aproximadamente, 28 dias $^{16}$ em uma estufa, cuja temperatura era de aproximadamente $37^{\circ} \mathrm{C}$ (Fig. 5).

\section{Procedimento do ensaio}

Passados 28 dias, as cargas eram removidas, para que os corpos-de-prova fossem submetidos aos testes de cisalhamento.

Para esse teste, foi utilizado um dispositivo onde era encaixado o corpo-de-prova e, em seguida, o braquete colado era envolvido manualmente por uma alça feita com fio metálico ${ }^{20} \mathrm{e}$, através da célula de carga (500kgf) da Máquina de Ensaios Universal (Kratos), esse fio era tracionado a uma velocidade de $0,5 \mathrm{~mm} / \mathrm{min}$ (Fig. 6, 7).

A Máquina de Ensaios Universal (Kratos) era então ativada e, por ser diretamente ligada a um computador, tão logo o braquete se descolasse do dente era registrada a força necessária para esse deslocamento, ou seja, o limite de resistência adesiva, em MPa.

\section{Tratamento estatístico}

Por se tratar de dois cimentos com sistemas de polimerização diferentes, e também de diferentes cargas usadas para os ensaios, foi utilizado o teste de Análise de Variância a dois critérios (ANOVA) para a análise dos resultados.

\section{RESULTADOS}

Os resultados, obtidos em $\mathrm{MPa}$, foram registrados pelo computador da máquina de ensaios quando da descolagem dos braquetes e podem ser observados nos gráficos 1 e 2 e tabela 1 .

Realizados os testes de cisalhamento, as superfícies dos dentes bovinos foram analisadas, através de uma lupa, o que permitiu determinar o tipo de fratura: adesiva (interface cimento/esmalte), coesiva (corpo do cimento) e fratura do esmalte. Salienta-se que não ocorreu, em nenhum corpo-

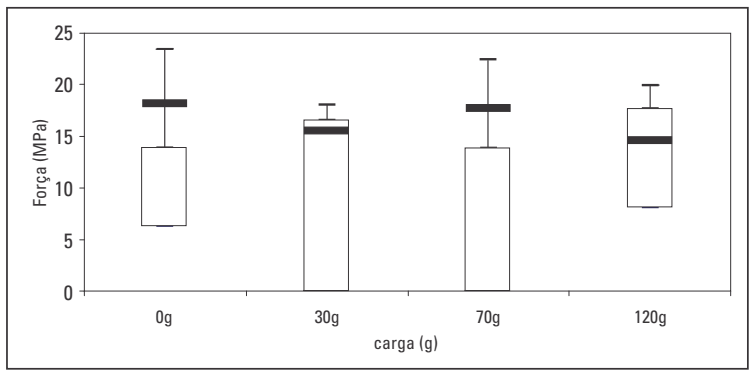

GRÁFICO 1 - Valores das resistências médias para o cimento Concise.

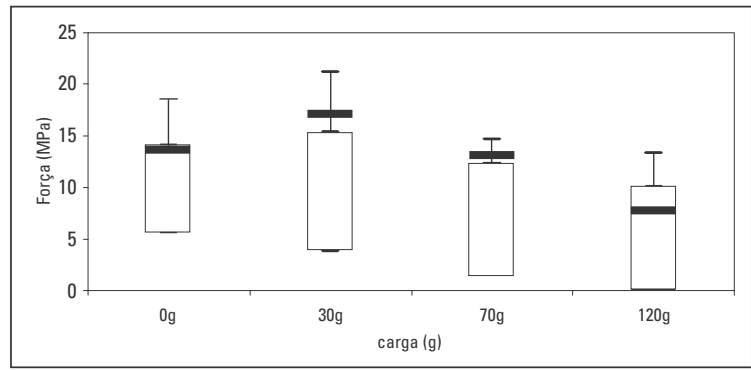

GRÁFICO 2 - Valores das resistências médias para o cimento Transbond XT.

Tabela 1 - Resultado da Análise de Variância a dois Critérios de classificação aplicada aos resultados dos testes.

\begin{tabular}{ll}
\hline & Valor de $\mathbf{p}$ (nível de significância) \\
\hline cimento & $0,000742^{*}$ \\
carga & 0,950855 \\
interação & 0,221730 \\
\hline
\end{tabular}

*Diferença estatisticamente significante $(p<0,01)$. 


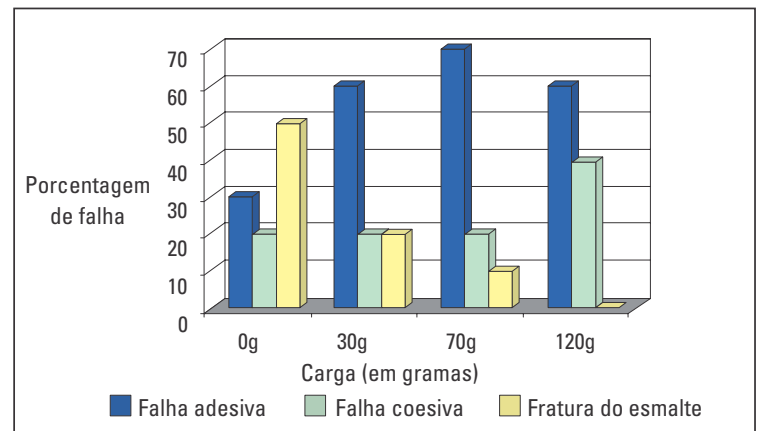

GRÁFICO 3 - Resultados das falhas adesivas com cimento Concise (em porcentagem).

de-prova, fratura adesiva na interface braquete/ cimento.

\section{Da metodologia}

A utilização de dentes bovinos para a realização deste trabalho foi motivada por trabalhos como os de Nakamichi, Fusayama ${ }^{13}$ e Haydar et al. ${ }^{6}$, onde os autores estudaram a possibilidade de substituir o dente humano em testes de adesão, uma vez que estes estão cada vez mais difíceis de serem obtidos, devido ao progresso do tratamento dentário conservativo. Esses trabalhos foram de grande valia, pois mostraram que não há diferença estatisticamente significante entre dentes bovinos e humanos, quando estes são utilizados para testes de adesão, principalmente quando se utiliza esmalte dentário. Como os dentes bovinos são facilmente encontrados, devido à presença de um grande frigorífico na cidade onde está instalada esta Faculdade de Odontologia, optou-se pela utilização desses dentes para a realização dos testes de resistência adesiva. Outro motivo pela escotha dos dentes bovinos foi a grande dificuldade na obtenção de dentes humanos e a necessidade de aprovação e consentimento por parte do Comitê de Ética.

Como as superfícies dos dentes bovinos são bastante irregulares, dificultando a colagem dos braquetes metálicos de base reta sobre as mesmas, optou-se pela planificação do esmalte dentário

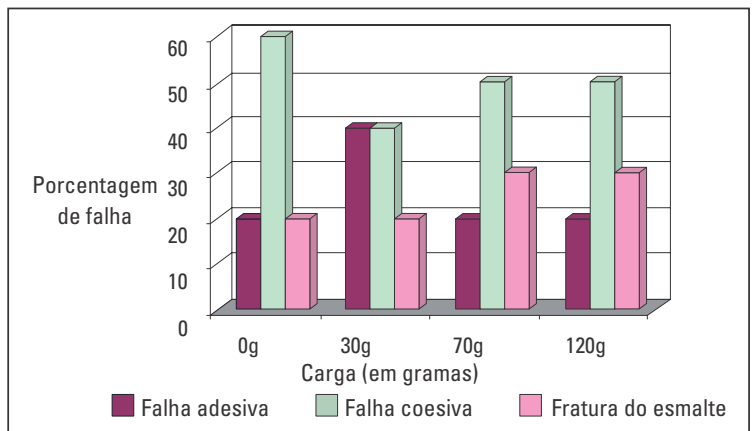

GRÁFICO 4 - Resultados das falhas adesivas com cimento Transbond XT (em porcentagem).

bovino, a fim de se padronizar a superfície a ser colada para que, no momento da cimentação dos braquetes, os cimentos pudessem ter uma espessura tão uniforme quanto possível.

Sendo assim, não houve necessidade de profilaxia prévia das superfícies dentárias, uma vez que o próprio polimento com lixas de maior e menor granulação, respectivamente, removia qualquer tipo de detritos que pudessem interferir nos ensaios, deixando a superfície plana e lisa, pronta para receber o condicionamento ácido proposto. Este foi o motivo pelo qual foram escolhidos os braquetes de base plana, para se excluir qualquer possibilidade de erros relacionados à superfície do tipo de dente escolhido, bem como a do tipo de braquete.

Apesar de existir no mercado uma gama de braquetes, confeccionados com diferentes tipos de materiais (cerâmicos, policarbonato, plásticos, entre outros), foram escolhidos os do tipo metálicos, pois são ainda os mais utilizados clinicamente $^{1,4,8,11,12,16,18}$.

A seleção dos cimentos utilizados para a colagem dos braquetes foi feita de acordo com os tipos mais comumente usados na clínica ortodôntica, sendo um de polimerização química (Concise Ortodôntico) e outro fotopolimerizável (Transbond $\mathrm{XT}$ ).

Por esse motivo, a seqüência de colagem se deu seguindo as instruções dos próprios fabricantes 
dos cimentos e, para a padronização da espessura de cimento entre o braquete e o dente, no ato da cimentação, foi utilizada uma Agulha Maior de Gilmore, que produz uma força (peso) de 453,6g, para os dois cimentos utilizados. Após a remoção do excesso dos cimentos e completa polimerização dos mesmos, a agulha era então removida.

Baseando-se nessa força de inclinação decidiuse avaliar se há ou não interferência de alguns fatores já citados, na resistência adesiva dos cimentos utilizados, bem como se uma subcarga (30g) e uma sobrecarga (120g) podem interferir diferentemente na mesma resistência.

Existem clínicos que instalam os arcos na mesma sessão em que os braquetes são $\operatorname{colados}^{20}$. Entretanto, para se evitar que o acessório se desloque, alguns profissionais optam por adiar esse procedimento. Neste trabalho optou-se pela colocação dos pesos 24 horas após, por ser o procedimento mais comum na clínica ortodôntica. As mais variadas condições de armazenamento dos corposde-prova são encontradas na literatura, razão pela qual não existe qualquer padronização para esse procedimento. A técnica que pareceu ser a mais utilizada pelos autores é a de manter os corposde-prova a $37^{\circ} \mathrm{C}$ a $100 \%$ de umidade relativa, durante 24 horas $^{9,11,20}$.

Depois de amarrados aos braquetes já colados aos dentes, os pesos tinham que ficar de tal maneira que exercessem força (carga) no sentido vertical e para baixo; para isso, uma grelha metálica especial foi confeccionada de modo que pudesse ficar imersa em água filtrada com os corpos-deprova dentro de uma caixa plástica por um período de 28 dias $^{17}$.

Durante a movimentação ortodôntica participam forças de compressão, tração, cisalhamento e torção ${ }^{20}$. Para este trabalho, decidiu-se pela força de tração durante a armazenagem e a força de cisalhamento na remoção dos braquetes, por ser o teste mais encontrado na literatura consul$\operatorname{tada}^{1,2,4,6,8-13,15,16,19,20,22,23}$, e à velocidade de $0,5 \mathrm{~mm} /$ $\min ^{4,11,20}$.
Existem, basicamente, duas maneiras de se realizar o teste de cisalhamento: através de lâminas pontiagudas que removem o braquete ${ }^{6}$ e através de alça metálica ${ }^{20}$ que, quando envolvida, apresenta mais pontos de contato com o braquete, descolando-o de maneira mais homogênea. Por esse motivo, o segundo método foi o escolhido.

\section{Dos resultados}

Segundo Haydar et al. $^{6}$, a resistência adesiva máxima recomendada para o sucesso na clínica ortodôntica está em torno de $7 \mathrm{MPa}$. Outro autor sugere que a resistência adesiva necessária para a clínica se encontra entre 5,9 e 7,9 $\mathrm{MPa}^{15}$, portanto, todos os resultados obtidos foram satisfatórios.

De acordo com a Análise de Variância a dois critérios de classificação empregada (carga e cimento), pode-se observar que houve diferença estatisticamente significante entre os cimentos Concise Ortodôntico e Transbond XT, porém não houve diferença entre as cargas testadas.

Observou-se, através das médias obtidas, que o cimento Concise Ortodôntico apresentou resultados maiores que os do cimento Transbond XT, e que ainda, através das médias obtidas, o Concise se mostrou menos sensível às diferentes forças utilizadas.

Embora não haja diferença estatisticamente significante, quando foi usada uma força de $120 \mathrm{~g}$ (a maior delas), o resultado para o Concise foi até maior que para os outros. Isso não pôde ser observado para o cimento Transbond XT onde, ainda que não existam diferenças significantes, numericamente notou-se uma diminuição nos valores dos resultados quando se aumenta a carga.

Para se observar até que ponto essa diminuição da resistência continuaria aumentando ou não, novos trabalhos são necessários, porque na literatura não se encontraram trabalhos observando a ação de pesos sobre os braquetes.

Dessa forma, para o grupo do cimento Concise Ortodôntico, com relação à fratura do esmalte nota-se que, quando o grupo controle é analisa- 
do, ou seja, o grupo sem carga alguma, há 50\% de fratura no esmalte contra $0 \%$ de fratura quando a carga é de 120g. Analisando o gráfico 3, fica nítida a diminuição da ocorrência de fratura no esmalte conforme aumenta a carga aplicada ao braquete. Clinicamente isso é importante, pois mostra que, conforme as forças vão atuando sobre o braquete, o cimento vai causando menos danos à estrutura dentária, preservando o esmalte no final do tratamento.

Com relação às falhas adesivas, que são aquelas que acontecem na interface esmalte/cimento (as mais desejadas, pois não deixam vestígios de resina na superfície dentária) ou então na interface cimento/braquete, observa-se que, conforme a carga é aumentada, aumenta-se também a porcentagem destas (neste caso falhas na interface esmalte/cimento, pois não foram notadas falhas na interface cimento/braquete) para o cimento Concise Ortodôntico (0g - 30\%, 30g - 60\% e 70g - 70\%), havendo um ligeiro declínio no caso dos $120 \mathrm{~g}$ (60\%).

As falhas coesivas, que são as fraturas no corpo do cimento, tiveram resultados constantes para o cimento de polimerização química $(0 \mathrm{~g}$ - 20\%, 30g - 20\% e $70 \mathrm{~g}$ - 20\%), havendo um aumento apenas no grupo onde a carga foi de $120 \mathrm{~g}(40 \%)$.

Já com o cimento fotopolimerizável Transbond $\mathrm{XT}$, as falhas adesivas se mostraram estáveis para os grupos $0 \mathrm{~g}(20 \%)$, $70 \mathrm{~g}(20 \%)$ e $120 \mathrm{~g}$ (20\%) e um pouco maiores no caso do grupo com $30 \mathrm{~g}(40 \%)$.

A porcentagem para falhas do tipo coesivas manteve-se constante no grupo do cimento fotopolimerizável, sendo que para os corpos-de-prova sem carga $(0 \mathrm{~g})$ a porcentagem chegou a $60 \%$ e nos outros grupos, 30g, 70g e $120 \mathrm{~g}$, a porcentagem de falha foi de $40 \%$, 50\% e 50\%, respectivamente.

As fraturas do esmalte dentário, para o grupo de braquetes colados com Transbond XT, permaneceram equilibradas entre os grupos $0 \mathrm{~g}$ e $30 \mathrm{~g}$ (20\%) e 70g e 120g (30\%) (Gráf. 4).

Levando-se em consideração as falhas adesivas após aplicação de carga, o grupo de braquetes colados com a resina Concise Ortodôntico obteve melhor resultado com relação à fratura de esmalte, uma vez que com carga a $120 \mathrm{~g}$ o índice de fratura foi $0 \%$.

As falhas adesivas na interface cimento/dente também evidenciaram melhor resultado com o grupo quimicamente ativado Concise Ortodôntico do que com o grupo fotopolimerizável Transbond $\mathrm{XT}$. Isso significa que, apesar deste cimento (Concise) apresentar uma resistência adesiva média maior (12,7MPa) do que o Transbond XT (9,25MPa), o mesmo não causa cause injúrias ao esmalte dentário conforme se aumenta a carga aplicada.

Esse fato, provavelmente, pode ser explicado pelas diferentes resistências coesivas dos dois cimentos. Outra hipótese seria a efetividade dos adesivos de esmalte por eles utilizados, porém, este não foi o propósito deste trabalho, o que deixa margem para futuras observações em novas pesquisas.

\section{CONCLUSÕES}

De acordo com o que foi observado neste trabalho, segundo a metodologia aplicada, pode-se concluir que:

- O cimento Concise Ortodôntico apresentou maior resistência à remoção que o cimento Transbond XT, para todas as cargas utilizadas $(\mathrm{p}<0,01)$.

- Não houve diferença estatisticamente significante na resistência adesiva frente às três cargas utilizadas (30g, 70g e 120g) para os dois cimentos testados.

- Quanto ao tipo de falha ocorrida no momento do deslocamento, o cimento Concise Ortodôntico mostrou-se mais sensivel às diferentes cargas do que o cimento Transbond XT, ou seja, conforme a carga aumentava, a porcentagem de fraturas no esmalte diminuía para o primeiro cimento, ao contrário do fotopolimerizável onde, em uma mesma situação, as fraturas no esmalte não sofreram alterações com o aumento das cargas e permaneceram equilibradas.

Enviado em: agosto de 2006 Revisado e aceito: julho de 2007 


\title{
Shear bond strength of orthodontic brackets using different static loading application
}

\begin{abstract}
Aim: The purpose of this study was to test differences on bond strength between auto-cured (Concise) and lightcured (Transbond XT) cements after static loading and shear test. Methods: Eighty bovine teeth and metallic orthodontic brackets (Morelli Ortodontia Braquete Edgewise/Rickets) were tested after static loads of 30, 70 and $120 \mathrm{grs}$. Bovine enamel was conditioned with $37 \%$ phosphoric acid gel for one minute, rinsed and dried. Adhesives were applied and brackets were bonded according to manufacturer's instructions. Cement thickness was standardized with the use of a heavier Gilmore needle. After 24 hours, half of the specimens were submitted to the static loads of 30, 70 and $120 \mathrm{grs}$. Control group remained unloaded. Then, specimens were immersed in distilled water for 28 days at $37^{\circ} \mathrm{C}$. Afterwards, orthodontic brackets were attached to a loop wire and submitted to a shear force (Máquina de Ensaios Kratos Universal Kratos) under a crosshead speed of $0.5 \mathrm{~mm} / \mathrm{min}$ and load cell of $500 \mathrm{Kgf}$. A two-way ANOVA test $(\alpha=0.05)$ was used to detect significant interactions between cements and static loads. Conclusions: (1) The Concise cement showed more statistically significant bond strength values than the Transbond XT cement for all static loads; (2) No statistically significant differences were observed regarding static loads for all cements tested and (3) Higher static loads provided less enamel fracture in the Concise group after shear test, whereas in the Transbond XT the rate of enamel fracture remained unchanged regardless of previous load applied.
\end{abstract}

Key words: Shear bond strength. Orthodontic bracket. Bonding. Load.

\section{REFERÊNCIAS}

1. ALEXANDER, J. C.; VIAZIS, A. D.; NAKAJIMA, H. Bond strengths and fracture modes of three orthodontic adhesives. J. Clin. Orthod., Boulder, v. 27, no. 4, p. 207-209, Apr. 1993.

2. BISHARA, S. E.; FONSECA, J. M.; BOYER, D. B. The use of debonding pliers in the removal of ceramic brackets: force levels and enamel cracks. Am. J. Orthod. Dentofacial Orthop., St. Louis, v. 108, no. 3, p. 242-248, Sept. 1995.

3. BUONOCORE, M. G. A simple method of increasing the adhesion of acrylic filling materials to enamel surface. J. Dent. Res., Alexandria, v. 34, no. 3, p. 849-853, Dec. 1955

4. CHAMDA, R. A.; STEIN, E. Time-related bond strengths of light cured and chemically cured bonding systems: an in vitro study. Am. J. Orthod. Dentofacial Orthop., St. Louis, v. 110, no. 4, p. 378-382, Oct. 1996.

5. DERRIC, R.; BEECH, D. R.; TEHERAH, J. Bonding of polimers to enamel: influence of deposits formend during etching, etching time and period of water immersion. J. Dent. Res., Alexandria, v. 59, p. 1156-1161, 1980

6. HAYDAR, B.; SARIKAYA, S.; ÇEHRELI, Z. C. Comparison of shear bond strength of three bonding agents with metal and ceramic brackets. Angle Orthod., Appleton, v. 69, no. 5, p. 457-462, Oct. 1999.

7. HUBERT, E. A. R. et al. Desenvolvimento de instrumental apropriado para medir a força de descolagem de braquetes ortodônticos, in vivo. J. Bras. Ortodon. Ortop. Facial Curitiba, v. 6, n. 33, p. 227-233, maio/jun. 2001.

8. IRELAND, A. J.; SHERRIFF, M. Use of an adhesive resin for bonding orthodontic brackets. Eur. J. Orthod., Oxford, v. 16, p. $27-34,1994$.
9. KHOWASSAH, M. A. et al. Effect of temperature and humidity on the adhesive strength of orthodontic direct bonding materials. J. Dent. Res., Alexandria, v. 54, no. 1, p. 146-151, Jan./Feb. 1975.

10. KNOLL, M.; GWINNETT, A. J.; WOLF, M. S. Shear strength of brackets bonded to anterior and posterior teeth. Am. J. Orthod., St. Louis, v. 89, no. 6, p. 476-479, June 1986.

11. MAIJER, R.; SMITH, D. C. Variables influencing the bond strength of metal orthodontic bracket bases. Am. J. Orthod., St. Louis, v. 79, no. 1, p. 20-34, Jan. 1981.

12. MONDELLI, A. L. Estudo comparativo da resistência adesiva da interface resina/bráquete, sob esforços de cisalhamento, empregando três resinas compostas e três tipos de tratamento na base do bráquete. 2004. $131 \mathrm{f}$. Tese (Doutorado) - Faculdade de Odontologia de Bauru, Universidade de São Paulo, Bauru, 2004

13. NAKAMICHI, M. I.; FUSAYAMA, T. Bovine teeth as a possible substitutes in the adhesion test. J. Dent. Res., Alexandria, v. 62, no. 10, p. 1076-1081, Oct. 1983.

14. NEWMAN, G. V. Adhesion and orthodontic plastic attachments. Am. J. Orthod. Dentofacial Orthop., St. Louis, v. 56, no. 6, p. 573-588, Dec. 1969

15. NEWMAN, G. V. et al. Update on bonding brackets: an in vitro survey. J. Clin. Orthod., Boulder, v. 28, no. 7, p. 396-402, July 1994.

16. NEWMAN, G. V. et al. Adhesion promoters, their effect on the bons strength of metal brackets. Am. J. Orthod. Dentofacial Orthop., St. Louis, v. 108, no. 3, p. 237-41, Sept. 1995

17. PROFFIT, W. R. Ortodontia contemporânea. 2. ed. Rio de Janeiro: Guanabara Koogan, 1995 
18. RETIEF, D. H. SADOWSKY, P. L. Clinical experience with the acid-etch technique in Orthodontics. Am. J. Orthod., St. Louis, v. 68, no. 6, p. 645-654, Dec. 1975.

19. ROCK, W. P. The effect of etching of human enamel upon bond strength with fissure sealant resins. Arch. Oral Biol., Oxford, v. 19, no. 10, p. 873-877, Oct. 1974

20. SOUZA, C. S. Comparação entre as resistências de união de cinco cimentos, utilizados na fixação de braquetes ortodônticos. 1999. 110 f. Dissertação (Mestrado)-Faculdade de Odontologia de Bauru, Universidade de São Paulo, Bauru, 1999
21. TRIMPENEERS, L. M.: DERMAUT, L. R. A clinical trial comparing the failure rates of two orthodontic bonding systems. Am. J. Orthod. Dentofacial Orthop., St. Louis, v. 110, no. 5, p. 547-550, Nov. 1996

22. URABE, H. et al. Combinations of etchants, composite resins, and bracket systems: an important choice in orthodontic bonding procedures. Angle Orthod., Appleton, v. 69, no. 3, p. 267-275, June 1999.

23. VICENTE, A. et al. A comparison of the shear bond strength of a resin cement and two orthodontic resin adhesive systems. Angle Orthod., Appleton, v. 75, no. 1, p. 109-113, Jan. 2005.

Endereço para correspondência

Carla Giannini

Avenida Brasil, 141, Jardim Paulista

CEP: 01.431-000 - São Paulo/SP

E-mail: gianninicarla@yahoo.com.br 